\title{
Managing the environment for health protection: research, policy and practice
}

\author{
Jeremy McAnultya,b,c
}

a Health Protection NSW, Sydney, Australia

b Guest Editor, Issue 2, 2016

c Corresponding author: jmcan@doh.health.nsw.gov.au

\section{Article history}

Publication date: April 2016 Citation: McAnulty J. Managing the environment for health protection: research, policy and practice. Public Health Res Pract. 2016;26(2):e2621613. doi: http:// dx.doi.org/10.17061/phrp2621613
Human exposures to environmental hazards lead to significant illness and death worldwide. In a recent report ${ }^{1}$, the World Health Organization estimated that 12.6 million people died from exposures to unhealthy environments in 2012 - nearly one in four deaths. Environmental factors - including polluted air, water and soil; chemical exposures; climate change and ultraviolet radiation - contributed to more than 100 diseases and injuries. Deaths were mainly from cardiovascular diseases (2.5 million deaths from stroke, 2.3 million deaths from ischaemic heart disease), intentional injuries and cancers (1.7 million deaths each) and chronic respiratory diseases (1.4 million deaths). Diarrhoeal diseases, respiratory infections, neonatal conditions and malaria each accounted for hundreds of thousands of deaths. Although the bulk of these exposures and diseases occurred in low- and middle-income countries - where people have too little access to clean drinking water, safe food and health services, and too much exposure to smoke, mosquitoes and dangerous workplaces - rich countries like Australia also have plenty of pollutants to worry about too.

The successful assessment of, and response to, environmental threats to health depend on effective collaborations between policy makers, public health practitioners and researchers across government agencies, industry and academia to ensure that real and potential threats are accurately assessed and controlled.

In this issue of Public Health Research \& Practice, themed 'Managing the environment for health protection: research, policy and practice', we look at a number of environmental hazards that affect human health, and the remediation being done, or that still needs to be done, to keep our population safe.

In a Perspective on the 'third wave' of asbestos harm, Armstrong and Driscoll caution that more evidence is needed to properly estimate the risk of asbestos exposure in the community, and to guide policy and action to reduce harm and cost. On the issue of safe drinking water, we publish two Perspectives on the importance of managing and monitoring water quality in the community: Byleveld and colleagues describe improvements to water quality in New South Wales (NSW), Australia, from recent quality assurance guidelines; and Jaravani and colleagues argue that, to help close the gap between Indigenous and non-Indigenous morbidity and mortality, more 
awareness is needed about Indigenous culture, history and attitudes to water.

In a Research article about nanomaterials and whether they should be treated as chemicals for regulatory purposes, Capon and colleagues find that communicating about nanomaterials in terms of chemical regulation may increase public angst because Australians perceive the risks from nanomaterials as lower than the risks from chemicals. And in the relatively new area of 'passive vaping', a review by Hess and colleagues finds that e-cigarette vapour has the potential to lead to adverse health effects, although it is likely to be less than the risk from tobacco smoke.

In a related Research article, Hefler and colleagues discuss the successes and unintended consequences of the first prison smoking ban in Australia, introduced in the Northern Territory in 2013, including the importance of a strong communication strategy and a long lead-in time to implementation.

In other contributions, a Brief report from $\underline{\text { Hirono }}$ and colleagues questions whether the Australian Government's commitment to the Trans-Pacific Partnership Agreement means Australia will face barriers to protecting its citizens from smoking and other harms. In a Research article, Dawson and colleagues find that the NSW influenza surveillance system delivers timely and good-quality information, but could be improved by being more flexible and stable, having automated systems, and formalising data collection. And finally, Fraser and colleagues evaluate the impact in the Northern Rivers region of NSW of a legislation amendment regarding child vaccination status in child-care centres, and find it fulfils its aim of prompting parents who had forgotten to vaccinate, but appeared to have little impact on 'conscientious objectors'.

Thank you to our growing band of readers for your support since Public Health Research \& Practice launched in November 2014. We aim to deliver engaging, high-quality, peer reviewed articles from Australian and international thought leaders, policy makers, practitioners and researchers that will inspire, provoke debate, and be useful in your work. Please encourage your colleagues to submit articles, subscribe to our quarterly email and follow us on Twitter (@phrpjournal). We invite you to submit manuscripts via our website, make suggestions about themes or topics, and send us your feedback.

\section{Competing interests}

None declared

\section{References}

1. Prüss-Ustün A, Wolf J, Corvalán C, Bos R, Neira M. Preventing disease through healthy environments: a global assessment of the burden of disease from environmental risks. Geneva: World Health Organization; 2016 [cited 2016 Mar 29]. Available from: apps.who. int/iris/bitstream/10665/204585/1/9789241565196_eng. pdf?ua $=1$

\section{Copyright: (c) (i) (2)}

(C) 2016 McAnulty. This article is licensed under the Creative Commons Attribution-NonCommercial-ShareAlike 4.0 International Licence, which allows others to redistribute, adapt and share this work non-commercially provided they attribute the work and any adapted version of it is distributed under the same Creative Commons licence terms. See: www.creativecommons.org/licenses/by-nc-sa/4.0/ 